Check for updates

Cite this: RSC Adv., 2017, 7, 43590

\title{
Large magnetocaloric effect and critical behavior in $\mathrm{La}_{0.7} \mathrm{Ba}_{0.2} \mathrm{Ca}_{0.1} \mathrm{Mn}_{1-x} \mathrm{Al}_{x} \mathrm{O}_{3}$
}

\begin{abstract}
M. A. Zaidi, (D)*a J. Dhahri, (D) ${ }^{b}$ I. Zeydi, ${ }^{\mathrm{c}}$ T. Alharbi $^{\mathrm{a}}$ and H. Belmabrouk ${ }^{\mathrm{a}}$
The structural, magnetic and magnetocaloric properties of $\mathrm{La}_{0.7} \mathrm{Ba}_{0.2} \mathrm{Ca}_{0.1} \mathrm{Mn}_{1-x} \mathrm{Al}_{x} \mathrm{O}_{3}(0 \leq x \leq 0.1)$ perovskite manganite oxides have been investigated. X-ray diffraction (XRD) analysis using Rietveld refinement has shown that all of the samples under investigation crystallize with a rhombohedric structure in the $R \overline{3} c$ space group ( $\left.N^{\circ} 167\right)$. Paramagnetic (PM) to ferromagnetic (FM) transitions have been observed in all of the synthesized samples. In addition, the maximum magnetic entropy change $\left(\Delta S_{M}^{\max }\right)$ for the $x=0$ sample was found to reach $\sim 5.8 \mathrm{~J} \mathrm{~kg}^{-1} \mathrm{~K}^{-1}$ under an applied magnetic field of $5 \mathrm{~T}$, which is sufficient for potential applications in magnetic refrigeration. For the same applied magnetic field $\left(\mu_{0} \mathrm{H}=5 \mathrm{~T}\right)$, the relative cooling power (RCP) value is found to be $167 \mathrm{~J} \mathrm{~kg}^{-1}$. The critical properties of manganites $\mathrm{La}_{0.7} \mathrm{Ba}_{0.2} \mathrm{Ca}_{0.1} \mathrm{Mn}_{1-x} \mathrm{Al}_{x} \mathrm{O}_{3}(\mathrm{O} \leq x \leq 0.1)$ are investigated through various techniques, such as modified Arrott plots, Kouvel-Fisher methods and critical isotherm analyses around the paramagnetic-ferromagnetic phase transition $\left(T_{\mathrm{c}}\right)$. The values of critical exponents, derived from magnetic data using the above methods, yield $0.246 \leq \beta \leq 0.253,1.01 \leq \gamma \leq 1.12$ and $4.76 \leq \delta \leq 4.9$ with a $T_{\mathrm{c}}$ of 300-350 K. The exponent values are close to those expected for tricritical mean field model

ferromagnets with short-range dipole-dipole interactions.
\end{abstract}

Received 24th July 2017

Accepted 28th August 2017

DOI: $10.1039 / \mathrm{c} 7 \mathrm{ra0} 8162 \mathrm{f}$

rsc.li/rsc-advances

\section{Introduction}

The discovery of colossal magnetic resistance (CMR) and the magnetocaloric effect (MCE) in mixed-valency manganese oxides $\operatorname{Tr}_{1-x} \mathrm{M}_{x} \mathrm{MnO}_{3}$ (where Tr stands for a trivalent rare-earth element such as $\mathrm{Sm}, \mathrm{Pr}, \mathrm{La}, \mathrm{Nd}$, etc., and $\mathrm{M}$ for a divalent alkaline earth ion such as $\mathrm{Ba}, \mathrm{Ca}, \mathrm{Pb}$ and $\mathrm{Sr}$ ) close to their paramagnetic semiconductor (PM-Sc) to ferromagnetic metal (FMM) transition temperatures has attracted much attention due to their extraordinary magnetic and electronic properties as well as their promise for the potential technological applications. ${ }^{1,2}$ The parent compound, $\mathrm{TrMnO}_{3}$ is a charge-transfer (CT) insulator with trivalent manganese ions in different layers coupled antiferromagnetically among themselves through a superexchange mechanism. However, within a layer, these $\mathrm{Mn}^{3+}$ ions are coupled ferromagnetically. When the $\mathrm{Tr}$ trivalent element is doped by various elements, a proportionate amount of $\mathrm{Mn}^{3+}$ with the electronic configuration $\left(3 \mathrm{~d}^{4}\right.$, $\left.\mathrm{t}_{2 \mathrm{~g}}^{3} \uparrow \mathrm{e}_{\mathrm{g}}^{1} \uparrow, S=2\right)$, is replaced by $\mathrm{Mn}^{4+}$ with the electronic configuration $\left(3 \mathrm{~d}^{3}, \mathrm{t}_{2 \mathrm{~g}}^{3} \uparrow \mathrm{e}_{\mathrm{g}}^{0}, S=3 / 2\right)$ creating holes in the $\mathrm{e}_{\mathrm{g}}$ band. $^{3}$ The holes permit charge transfer in the $e_{g}$ state which is highly hybridized with the oxygen $2 p$ state. Due to the intra-

${ }^{a}$ College of Science of Zulfi, Majmaah University Saudi Arabia, Saudi Arabia. E-mail: mohamedzaidi215@yahoo.com

${ }^{b}$ Laboratory of Condensed Matter and Nanoscience, Faculty of Sciences of Monastir, University of Monastir, 5019, Tunisia

'Université De Monastir, Laboratoire de Micro-optoélectroniques et Nanostructures (LMON), Monastir 5000, Tunisia atomic Hund's rule, this charge transfer induces a ferromagnetic coupling between $\mathrm{Mn}^{3+}$ and $\mathrm{Mn}^{4+}$ ions which in turn has a dramatic effect on the electrical conductivity., ${ }^{4,5}$ This doubleexchange (DE) model originally proposed by Zener ${ }^{6}$ has been the most prominent underlying physics that describes the simultaneous occurrence of transition from paramagnetic semiconductor to ferromagnetic metal for most hole-doped manganites. The perovskite structure generally shows lattice distortion as a modification from the idea cubic structure to orthorhombic or rhombohedric structure mainly due to JahnTeller (JT) effect causing the deformation of the $\mathrm{MnO}_{6}$ octahedron. Therefore, to understand better the relation between semiconductor-metal transition and CMR effect, two important questions about PM-FM transition should be clarified: one is the order of phase transition; the other is the common universality class. To make these issues clear, it is necessary to investigate in details the critical exponents at the region of the PM-FM transition. The analysis of the critical exponents in the vicinity of the magnetic phase transition is a powerful tool to investigate in details the mechanisms of the magnetic interaction responsible for the transition ${ }^{7,8}$ in earlier theoretical works, the critical behaviour related to the PM to FM transition in manganites within the double exchange (DE) model was described in the framework of long range mean field theory. ${ }^{9}$ However, recent theoretical calculations have predicted that the critical exponents in manganites are in agreement with a short range exchange interaction model. ${ }^{10,11}$ Claiming the essential validity of the DE model, Motome and Furukawa ${ }^{12}$ argue, based 
on computational studies for DE models, that the PM-FM transition in these doped ferromagnetic manganites should belong to the short-range Heisenberg universality class. ${ }^{12,13}$ Moreover, a few relevant experimental investigations on the critical phenomena also supported this viewpoint due to the obtained value of the critical exponents consistently with that in the conventional ferromagnet of 3D-Heisenberg model. Ghosh et $a l .{ }^{14}$ reported that the calculated values of the critical exponent $\beta(=0.37)$ for $\mathrm{La}_{0.7} \mathrm{Sr}_{0.3} \mathrm{MnO}_{3}(\beta=0.365$ in Heisenberg model). However, a relative high value of $\beta=0.5$ obtained in $\mathrm{La}_{0.8} \mathrm{Sr}_{0.2} \mathrm{MnO}_{3}$ is in good agreement with that in mean-field model. ${ }^{15}$ In the contrary, a very low critical exponent of $\beta=$ 0.14 identified in the single crystal $\mathrm{La}_{0.7} \mathrm{Ca}_{0.3} \mathrm{MnO}_{3}$ suggested that the PM-FM transition in this system is of first order rather than second order. ${ }^{16}$ Therefore, in view of the varied critical exponent $\beta$ from 0.1 to 0.5 , currently, four kinds of different theoretical models, mean-field $(\beta=0.5), 3 \mathrm{D}$-Heisenberg $(\beta=$ $0.365), 3 \mathrm{D}$-Ising $(\beta=0.325)$ and tricritical mean field $(\beta=0.25)$ were used to explain the critical properties in manganites. Due to the divergence in these reported critical values, it is worthwhile to study the critical behavior in the same perovskite manganites. Due to the divergence in these reported critical values, it is worthwhile to study the critical behavior in the same perovskite manganites. In this paper, we present a detailed study of structural, magnetic, magnetocaloric and the critical phenomena in $\mathrm{La}_{0.7} \mathrm{Ba}_{0.2} \mathrm{Ca}_{0.1} \mathrm{Mn}_{1-x} \mathrm{Al}_{x} \mathrm{O}_{3}(0 \leq x \leq 0.1)$, using the isothermal magnetization around $T_{\mathrm{c}}$.

\section{Experiment}

The doped perovskite manganites $\mathrm{La}_{0.7} \mathrm{Ba}_{0.2} \mathrm{Ca}_{0.1} \mathrm{Mn}_{1-x} \mathrm{Al}_{x} \mathrm{O}_{3}(0$ $\leq x \leq 0.1$ ) were prepared by sol-gel technique using metal nitrates as starting materials. In this method, the stoichiometric amounts of metal nitrates in the form of solution were converted into citrates and $\mathrm{pH}$ was adjusted between 6.5 and 7. After getting a sol on slow evaporation, a gelating reagent, ethylene glycol was added and heated between $150{ }^{\circ} \mathrm{C}$ and $180{ }^{\circ} \mathrm{C}$ to get a gel. This solution on further heating yields a dry fluffy porous mass, which was calcined at $650{ }^{\circ} \mathrm{C}$ for $10 \mathrm{~h}$. Then the powder was pressed into pellets and finally sintered in air at $900{ }^{\circ} \mathrm{C}$ for $12 \mathrm{~h}$.

The structure and purity phase of the samples were checked at room temperature by means of X-ray powder diffraction (XRD) using CuK $\alpha$ radiation $(\lambda=1.5406 \AA)$. The data collection was performed by step-scan modes, in a $2 \theta$ range between $20^{\circ}$ and $92^{\circ}$ with step-size of $0.017^{\circ}$ and step time of $18 \mathrm{~s}$. The structural parameters were obtained by fitting the experimental data of XRD using the Rietveld structural refinement program FULLPROF soft-ware (Version 1.9c-May 2001-LLB-JRC). ${ }^{17}$ Magnetic measurements were performed by using BS1 and BS2 magnetometer developed in Louis Neel Laboratory at Grenoble. Magnetization $(M) v s$. magnetic field $\left(\mu_{0} H\right)$, varying from 0 to $5 \mathrm{~T}$ at different temperatures $(T)$, was measured by magnetometer. For the studies, the isothermal $M$ vs. $\mu_{0} H$ is corrected by a standard procedure from low field dc magnetization measurements. In fact, the internal field used for the scaling analysis has been corrected for demagnetization, $\mu_{0} H=\mu_{0} H_{\text {appl }}$
- $D_{\mathrm{a}} M$, where $D_{\mathrm{a}}$ is the demagnetization factor obtained from $M$ vs. $H$ measurements in the low-field linear-response regime at a low temperature.

\section{Results and discussion}

The results of X-ray diffraction indicate that all samples are single-phase perovskite manganites. Fig. 1 presents the X-ray pattern of $x=0$. Formation of single phase was confirmed by absence of characteristic XRD lines of constituent oxides or the other phases in the powder X-ray diffraction patterns for all compositions, within the sensitivity limits of the experiment (a few percent). The crystal structure of $\mathrm{La}_{0.7} \mathrm{Ba}_{0.2} \mathrm{Ca}_{0.1} \mathrm{Mn}_{1-x} \mathrm{Al}_{x} \mathrm{O}_{3}$ $(0 \leq x \leq 0.1)$ samples is determined to be rhombohedral structure with the $R \overline{3} c$ space group, hexagonal setting $(z=6)$. The $(\mathrm{La} / \mathrm{Ba} / \mathrm{Ca})$ atoms are at $6 \mathrm{a}(0,0,1 / 4),(\mathrm{Mn} / \mathrm{Al})$ at $6 \mathrm{~b}(0,0,0)$ and $\mathrm{O}$ at $18 \mathrm{e}(x, 0,1 / 4)$ positions. The results of refinement are listed in Table 1. In this table, the residuals for the weighted pattern $R_{\mathrm{wp}}$, the pattern $R_{\mathrm{p}}$, the structure factor $R_{\mathrm{F}}$, and the goodness of fit $\chi^{2}$ are also reported. The decreasing in the lattice constant and the unit cell volume can be related to the smaller ionic radius of $\mathrm{Al}$ ion $\left(r_{\mathrm{Al}}{ }^{3+}=0.535 \AA\right.$ and $r_{\mathrm{Mn}}{ }^{3+}=0.645 \AA$ (ref. 18)). This was confirmed by the determination by Rietveld refinement of $(\mathrm{Mn} / \mathrm{Al})-\mathrm{O}$ distance calculated from the structural parameters (see Table 1).

The tilting of the octahedra can also be realized looking the Goldschmidt tolerance factor $(t), t=\frac{r_{\mathrm{A}}+r_{\mathrm{O}}}{\sqrt{2}\left(r_{\mathrm{B}}+r_{\mathrm{O}}\right)}$ where $r_{\mathrm{A}}$ and $r_{\mathrm{B}}$ are average ionic radii of $\mathrm{A}$ - and B-site atoms and $r_{\mathrm{O}}$ is the ionic radii of $\mathrm{O}^{2-}$. Oxide based manganite compounds have a perovskite structure if their tolerance factor lies in the limits of $0.75<t<1$ and in an ideal case the value must be equal to unity. As the calculated values of all the samples of the present investigation are within range (Table 1), one may conclude that they might be having a stable perovskite structure. The

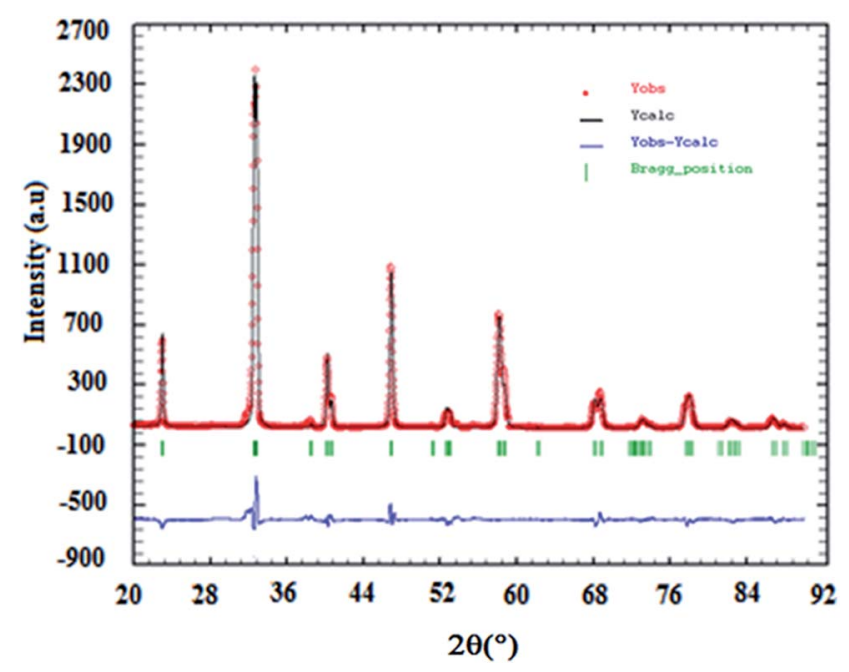

Fig. 1 Rietveld analysis results for $x=0.10$ sample. Observed $\left(Y_{\text {obs }}\right)$ and calculated ( $\left.Y_{\text {calc }}\right)$ patterns are compared (blue line). The vertical ticks show the positions of the calculated Bragg reflections for the rhombohedric phase ( $R 3 c$ space group). 
Table 1 Room-temperature structural parameters ( $X$-ray Rietveld refinement) for $\mathrm{La}_{0.7} \mathrm{Ba}_{0.2} \mathrm{Ca}_{0.1} \mathrm{Mn}_{1-x} \mathrm{Al}_{x} \mathrm{O}_{3}(0 \leq x \leq 0.10)$ manganites. The numbers in parentheses are estimated standard deviations to the last significant. $B_{\text {iso: }}$ : the isotropic Debye-Waller factor. Agreement factors of profile $R_{\mathrm{p}}$, weighted profile $R_{\mathrm{wp}}$ and structure $R_{\mathrm{F}} \cdot \chi^{2}$ : the goodness of fit ${ }^{a}$

\begin{tabular}{llll}
\hline Samples & & & \\
\hline$x$ & 0.0 & 0.05 & 0.10 \\
\hline $\boldsymbol{R} \overline{3} \boldsymbol{c}$ phase & & & \\
$a(\AA)$ & $5.5078(4)$ & $5.5012(5)$ & $5.4966(7)$ \\
$c(\AA)$ & $13.4645(9)$ & $13.4641(4)$ & $13.4628(4)$ \\
$V\left(\AA^{3}\right)$ & 353.73 & 352.87 & 352.25 \\
$B_{\text {iso }}(\mathrm{La} / \mathrm{Pb} / \mathrm{Na})\left(\AA^{2}\right)$ & $0.28(4)$ & $0.35(2)$ & $0.68(5)$ \\
$x(\mathrm{O})$ & $0.4974(3)$ & $0.4562(2)$ & $0.4368(1)$ \\
$B_{\text {iso }}(\mathrm{O})\left(\AA^{2}\right)$ & $0.84(4)$ & $0.96(3)$ & $1.21(1)$ \\
$d_{\mathrm{Mn}-\mathrm{O}}(\AA)$ & 1.948 & 1.952 & 1.955 \\
$\theta_{\mathrm{Mn}-\mathrm{O}-\mathrm{Mn}}\left({ }^{\circ}\right)$ & 165.27 & 162.88 & 161.45 \\
$S_{\mathrm{G}}(\mathrm{nm})$ & 65 & 43 & 39 \\
$D_{\mathrm{MEB}}(\mathrm{nm})$ & 107 & 91 & 68 \\
$t$ & 0.942 & 0.945 & 0.957 \\
$W\left(10^{-2}\right)$ & 9.61 & 9.52 & 9.44 \\
& & & \\
Discrepancy factors & & & \\
$R_{\mathrm{wp}}(\%)$ & 6.41 & 4.93 & 2.38 \\
$R_{\mathrm{p}}(\%)$ & 4.21 & 2.28 & 3.82 \\
$R_{\mathrm{F}}(\%)$ & 3.18 & 2.38 & 3.12 \\
$\chi^{2}(\%)$ & 2.47 & 2.08 & 2.27 \\
& & &
\end{tabular}

${ }^{a}$ Weight fraction resulting from the Rietveld analysis is expressed in percent of $\mathrm{La}_{0.7} \mathrm{Ba}_{0.2} \mathrm{Ca}_{0.1} \mathrm{Mn}_{1-x} \mathrm{Al}_{x} \mathrm{O}_{3} . \quad a$ and $c$ : hexagonal cell parameters; $V$ : cell volume; $B_{\text {iso }}$ : isotropic thermal parameter; $x$ : oxygen position; $R_{\mathrm{wp}}, R_{\mathrm{p}}$ and $R_{\mathrm{F}}$ : the residuals for, respectively, the weighted pattern, the pattern and the Bragg structure factor; $\chi^{2}$ : the goodness of fit.

rhombohedral distortion may be viewed as a rotation of the octahedral around the three-fold axis by an angle $\omega$ from the ideal perovskite position. This rotation describes the buckling of the $\mathrm{MnO}_{6}$ octahedra caused by ionic radii mismatch between $\mathrm{A}$ and $\mathrm{B}$ cations. The angle of rotation $\omega$ may be calculated from the oxygen position using $\omega=\arctan (\sqrt{ } 3-x \sqrt{ } 12) .{ }^{19}$ The values obtained are 7.52, 8.61 and 9.84 for $x=0,0.05$ and 0.10 , respectively, indicating large distortions for all the compositions. For regular $\mathrm{Mn}$ coordination octahedra the relation between $\omega$ and superexchange $(\mathrm{Mn}, \mathrm{Al})-\mathrm{O}-(\mathrm{Mn}, \mathrm{Al})$ bond angle is given by $\cos \theta=\left(1-4 \cos ^{2} \omega\right) / 3{ }^{20}$ Using the values of $\omega$, we obtain a reasonable agreement with that obtained from refinement (Table 1). The departure from $180^{\circ}$ of $(\mathrm{Mn}, \mathrm{Al})-\mathrm{O}-$ $(\mathrm{Mn}, \mathrm{Al})$ angle is a measure of the distortion. The variations of the bond length $d(\mathrm{Mn} / \mathrm{Al})-\mathrm{O}$ and of bond angle $(\mathrm{Mn} / \mathrm{Al})-\mathrm{O}-(\mathrm{Mn} / \mathrm{Al})$ have opposite effects on the unit-cell volume. For a distorted perovskite, they are related $\mathrm{by}^{21} V=z\left[2 d_{(\mathrm{Mn}, \mathrm{Al})-\mathrm{O}} \cos \omega\right]^{3}$ where $\omega=\pi-\theta_{(\mathrm{Mn}, \mathrm{Al})-\mathrm{O}-(\mathrm{Mn}, \mathrm{Al})} / 2$ and $z$ is the number of formula units in the unit cell ( $z=6$ in our case). The functional dependence of volume as a function of concentration $x$ of $\mathrm{Al}$ is reproduced using the observed values of $d_{(\mathrm{Mn}, \mathrm{Al})-\mathrm{O}}$ and $\theta_{\mathrm{Mn}-\mathrm{Al}-\mathrm{O}-\mathrm{Mn}-\mathrm{Al}}$ in the above expression.

In order to check the existence of all elements in the compounds energy dispersive X-ray analysis was performed. The EDX spectra represented in Fig. 2 reveals the presence of $\mathrm{La}$, $\mathrm{Ba}, \mathrm{Ca}, \mathrm{Mn}$ and $\mathrm{Al}$, which confirms that there is no loss of any integrated element during the sintering. The EDX analysis shows that the chemical compositions of these compounds are close to the nominal ones (La: $\mathrm{Ba}: \mathrm{Ca}: \mathrm{Mn}: \mathrm{Al}=$ $0.7: 0.2: 0.1: 1-x: x)$. The typical cationic composition for the samples is represented in Table 2 . These results are very close to the nominal ones within the experimental uncertainties and, since no secondary phases are seen in the XRD patterns, it is reasonable to assume that aluminium has been substituted for $\mathrm{Mn}$ in these samples. The inset of Fig. 2 shows the scanning electron microscopy (SEM) photograph for the $\mathrm{La}_{0.7} \mathrm{Ba}_{0.2} \mathrm{Ca}_{0.1^{-}}$ $\mathrm{Mn}_{1-x} \mathrm{Al}_{x} \mathrm{O}_{3}(0 \leq x \leq 0.1)$ samples. The average calculated crystallite size value is given in Table 1 . Obviously, the particle sizes $D_{\text {MEB }}$ observed by SEM are much larger than those calculated $S_{\mathrm{G}}(\mathrm{nm})$ by $\mathrm{XRD}$, which indicates that each particle observed by SEM consists of several crystallites.

In order to study the aluminum effect on the magnetic properties, magnetization variation $v s$. temperature under an applied magnetic field of $0.05 \mathrm{~T}$ is measured and reported in

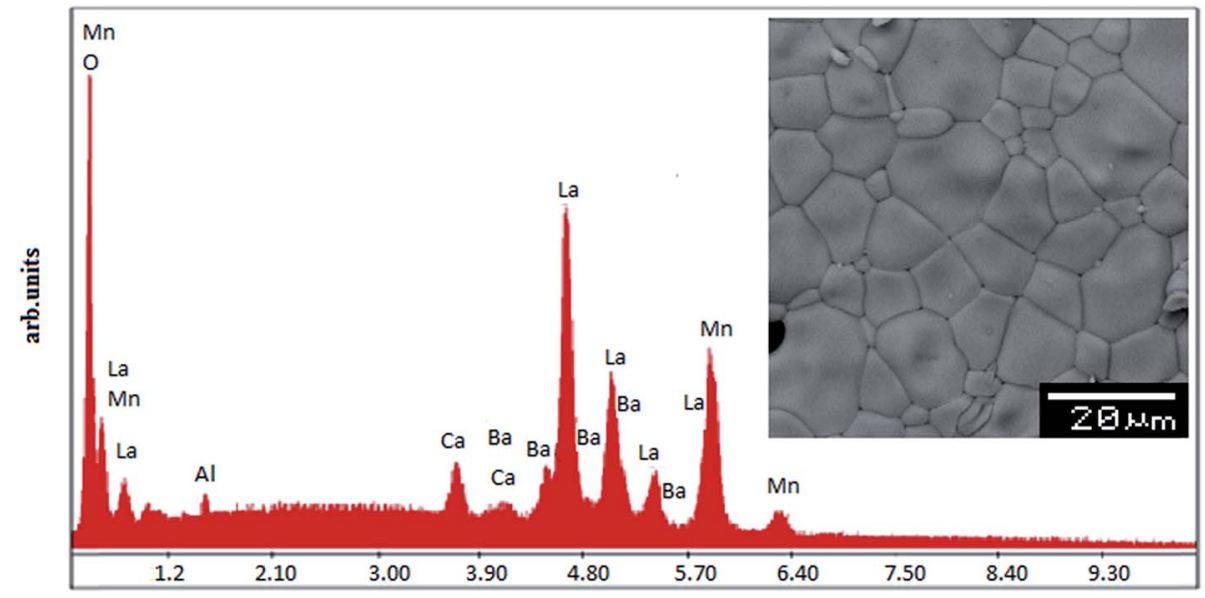

Fig. 2 EDAX spectrum for 0.1. The insets shows the typical SEM. 
Table 2 Results of EDAX analysis

Typical cationic composition from EDX

\begin{tabular}{lllllll} 
Composition & $\mathrm{La}$ & $\mathrm{Ba}$ & $\mathrm{Ca}$ & $\mathrm{Mn}$ & $\mathrm{Al}$ & Nominal composition \\
\hline$x=0.00$ & 0.695 & 0.202 & 0.098 & 1.007 & - & $\mathrm{La}_{0.7} \mathrm{Ba}_{0.2} \mathrm{Ca}_{0.1} \mathrm{MnO}_{3}$ \\
$x=0.05$ & 0.696 & 0.198 & 0.096 & 0.952 & 0.051 & $\mathrm{La}_{0.7} \mathrm{Ba}_{0.2} \mathrm{Ca}_{0.1} \mathrm{Mn}_{0.95} \mathrm{Al}_{0.05} \mathrm{O}_{3}$ \\
$x=0.10$ & 0.698 & 0.203 & 0.101 & 0.899 & 0.103 & $\mathrm{La}_{0.7} \mathrm{Ba}_{0.2} \mathrm{Ca}_{0.1} \mathrm{Mn}_{0.9} \mathrm{Al}_{0.1} \mathrm{O}_{3}$
\end{tabular}

Fig. 3. This curves reveal that all samples exhibit a ferromagnetic-paramagnetic transition occurring at the Curie temperature $\left(T_{\mathrm{C}}\right)$ when increasing temperature. The evolution of $\mathrm{d} M / \mathrm{d} T$ versus temperature $(T)$ is reported in the inset of Fig. 3. The values of the Curie temperature $T_{\mathrm{C}}$ decreases from $350 \mathrm{~K}$ to $300 \mathrm{~K}$ when the continent $x$ increases. Similar to the previous studies, ${ }^{22,23}$ an $x$ increase in $\mathrm{La}_{0.7} \mathrm{Ba}_{0.2} \mathrm{Ca}_{0.1} \mathrm{Mn}_{1-x} \mathrm{Al}_{x} \mathrm{O}_{3}$ decreases gradually the $T_{\mathrm{C}}$ towards room temperature. This is due to a decrease in the ferromagnetic phase which could be explained as follows. An $x$ increase introduces more $\mathrm{Mn}^{4+}$ ions and disadvantages the dual FM double-exchange interactions of $\mathrm{Mn}^{4+}-\mathrm{Mn}^{3+}$ pairs. Meanwhile, antiferromagnetic superexchange interactions of $\mathrm{Mn}^{4+}-\mathrm{Mn}^{4+}$ are significant.

Based on the model of double exchange, a lower $T_{\mathrm{C}}$ corresponds to a poor overlap between $\mathrm{Mn} \mathrm{3d}$ and $\mathrm{O} 2 \mathrm{p}$ orbitals, resulting in a reduced bandwidth $W \propto \frac{\cos \left[1 / 2\left(\pi-\theta_{\mathrm{Mn} / \mathrm{Al}-\mathrm{O}-\mathrm{Mn} / \mathrm{Al}}\right)\right]}{\left(d_{\mathrm{Mn} / \mathrm{Al}-\mathrm{O}}\right)^{3.5}},{ }^{24}$ where $\theta_{\mathrm{Mn} / \mathrm{Al}-\mathrm{O}-\mathrm{Mn} / \mathrm{Al}}$ is the angle and $d_{\mathrm{Mn} / \mathrm{Al}-\mathrm{O}}$ is the bond length. The increase of the $\mathrm{Mn} / \mathrm{Al}-\mathrm{O}$ bond length reduces the overlap between $\mathrm{Mn}(3 \mathrm{~d})$ and $\mathrm{O}(2 \mathrm{p})$ orbital's and leads to the decrease of $W$ (Table 1$)$, which results in the decrease of Curie temperature.

In the paramagnetic region, the susceptibility $(\chi)$ follows the Curie-Weiss law and can be then written: $\chi=\frac{C}{T-\theta_{\mathrm{CW}}}$, where $C$ is the Curie constant and $\theta_{\mathrm{CW}}$ is the Curie-Weiss temperature.

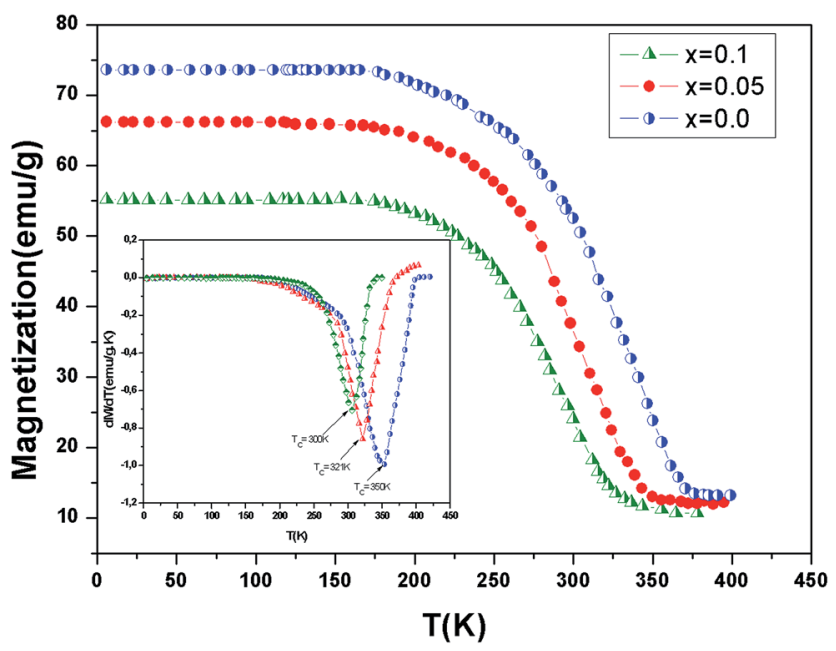

Fig. 3 Temperature dependence of magnetization for $\mathrm{La}_{0.7} \mathrm{Ba}_{0.2^{-}}$ $\mathrm{Ca}_{0.1} \mathrm{Mn}_{1-x} \mathrm{Al}_{x} \mathrm{O}_{3}(0 \leq x \leq 0.1)$ samples measured at $\mu_{0} \mathrm{H}=0.05 \mathrm{~T}$. The inset shows the $\mathrm{d} M / \mathrm{d} T$ curves for $x=0.0,0.05$ and $x=0.10$.
By fitting the linear paramagnetic region to the Curie-Weiss equation, parameters $C$ and $\theta_{\mathrm{CW}}$ were obtained. The effective paramagnetic moments were calculated from the Curie constant using the equation $C=\frac{N_{\mathrm{A}} \mu_{\mathrm{B}}{ }^{2}}{3 k_{\mathrm{B}}} \mu_{\mathrm{eff}}{ }^{2},{ }^{25}$ where $N_{\mathrm{A}}=6.023$ $\times 10^{23} \mathrm{~mol}^{-1}$ is the number of Avogadro, $\mu_{\mathrm{B}}=9.274 \times 10^{-21}$ emu is the Bohr magneton and $k_{\mathrm{B}}=1.38016 \times 10^{-16} \mathrm{erg} \mathrm{K}^{-1}$ is the Boltzmann constant. For $\mathrm{Mn}^{3+}$ or $\mathrm{Mn}^{4+}$, the orbital moment is quenched $(L=0)$ so that $S$ is the appropriate quantum number and we can write $\mu_{\text {eff }}(S)=g \mu_{\mathrm{B}} \sqrt{S(S+1)}$, where $g$ factor is equal to 2 and $S=3 / 2$ for $\left(\mathrm{Mn}^{4+}, 3 \mathrm{~d}^{3}\right)$ or 2 for $\left(\mathrm{Mn}^{3+}\right.$, $\left.3 \mathrm{~d}^{4}\right)$. The $\mu_{\text {eff }}$ value is between the spin only values for $\mathrm{Mn}^{4+}$ (3.87 $\left.\mu_{\mathrm{B}}\right)$ and $\mathrm{Mn}^{3+}\left(4.9 \mu_{\mathrm{B}}\right)$ ions. ${ }^{26}$ The theoretical effective magnetic moment total $\left(\mu_{\text {eff.tot }}^{\text {theor }}\right)$ can be written in the form:

$$
\mu_{\text {eff.tot }}^{\text {theor }}=\sqrt{(0.7-x) \mu_{\text {eff }}^{2}\left(\mathrm{Mn}^{3+}\right)+(0.3) \mu_{\text {eff }}^{2}\left(\mathrm{Mn}^{4+}\right)}
$$

The percentage of $\mathrm{Mn}^{3+}$ and $\mathrm{Mn}^{4}$ ions in our samples is tested by the conventional chemical technique. First, we have dissolved our powder in oxalic acid dishydrate $\left(\mathrm{H}_{2} \mathrm{C}_{2} \mathrm{O}_{4}, 2 \mathrm{H}_{2} \mathrm{O}\right)$ and concentrated sulfuric acid $\left(\mathrm{H}_{2} \mathrm{SO}_{4}\right)$. Then, the resulting solutions were titrated by potassium permanganate $\left(\mathrm{KMnO}_{4}\right)$. The results showed that the experimental values of manganese ions concentration (for example $x=0.00)\left(\mathrm{Mn}^{3+}(\%)=70.4\right.$ and $\left.\mathrm{Mn}^{4+}(\%)=29.8\right)$ are close to the theoretical ones.

Fig. 4 shows the inverse magnetic susceptibility $\chi^{-1}(\mathrm{~T})$ as a function of temperature for the samples at $0.05 \mathrm{~T}$. By fitting the linear paramagnetic region to the Curie-Weiss equation, parameters $C$ and $\theta_{\mathrm{CW}}$ were obtained. In Table 3 , experimental values of temperature $T_{\mathrm{C}}$, the Curie-Weiss temperature $\theta_{\mathrm{CW}}$, the theoretical $\left(\mu_{\mathrm{eff} . t o t}^{\text {theo }}\right)$ and experimental $\left(\mu_{\mathrm{eff}}^{\mathrm{exp}}\right)$ values of effective magnetic moment, obtained for all the samples are given. Generally, the difference between $T_{\mathrm{C}}$ and $\theta_{\mathrm{CW}}$ depends on the substance and it is associated with presence of short-range ordered slightly above $T_{\mathrm{C}}$, which may be related to the presence of a magnetic inhomogeneity. As seen in Table $3, \theta_{\mathrm{CW}}$ is positive and decreases with $x$ and thus follows the same trend of $T_{\mathrm{C}}$. The positive value of $\theta_{\mathrm{CW}}$ indicates the ferromagnetic interaction between spins. In our case, small difference between the experimental $\mu_{\text {eff }}^{\text {exp }}$ value and the theoretical $\mu_{\text {eff.tot }}^{\text {theor }}$ value, as well as slight $\mu_{\text {eff }}$ variation with (Al) content change can be caused by presence of the short range ferromagnetic correlation between $\mathrm{Mn}^{4+}$ and $\mathrm{Mn}^{3+}$ ions. ${ }^{27}$

Magnetization versus field $\left(M-\mu_{0} H\right)$ curve of $\mathrm{La}_{0.7} \mathrm{Ba}_{0.2} \mathrm{Ca}_{0.1^{-}}$ $\mathrm{Mn}_{1-x} \mathrm{Al}_{x} \mathrm{O}_{3}$ at $5 \mathrm{~K}$ is plotted inset Fig. 4. The sample reaches nearly a constant value of magnetization under a field $\mu_{0} H=1.5 \mathrm{~T}$. 


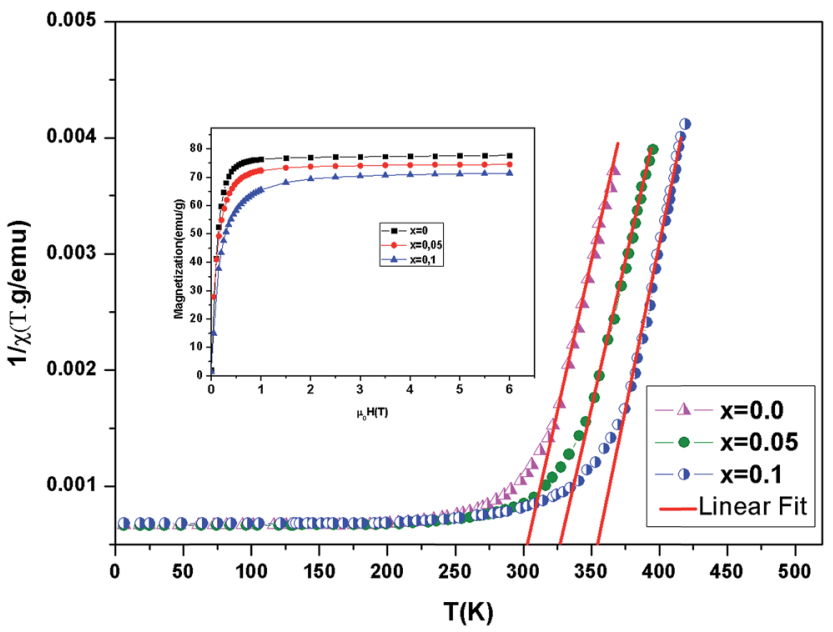

Fig. 4 Temperature dependence of the inverse magnetic susceptibility for $\mathrm{La}_{0.7} \mathrm{Ba}_{0.2} \mathrm{Ca}_{0.1} \mathrm{Mn}_{1-x} \mathrm{Al}_{x} \mathrm{O}_{3}(\mathrm{O} \leq x \leq 0.1)$ samples. Inset magnetization versus field $\left(M-\mu_{0} H\right)$ curves for $\mathrm{La}_{0.7} \mathrm{Ba}_{0.2} \mathrm{Ca}_{0.1} \mathrm{Mn}_{1-x^{-}}$ $\mathrm{Al}_{x} \mathrm{O}_{3}$ at $5 \mathrm{~K}$.

Table 3 Values of transition temperature $T_{C}$, Curie-Weiss temperature $\theta_{\mathrm{CW}}$, experimental $\mu_{\mathrm{eff}}^{\mathrm{exp}}$ and calculated $\mu_{\mathrm{eff}}^{\mathrm{cal}}$ effective paramagnetic moments in $\mathrm{La}_{0.7} \mathrm{Ba}_{0.2} \mathrm{Ca}_{0.1} \mathrm{Mn}_{1-x} \mathrm{Al}_{x} \mathrm{O}_{3}$

\begin{tabular}{lllll}
\hline Composition & $T_{\mathrm{C}}(\mathrm{K})$ & $\mu_{\text {eff.tot }}^{\text {theo }}\left(\mu_{\mathrm{B}}\right)$ & $\mu_{\text {eff }}^{\exp }\left(\mu_{\mathrm{B}}\right)$ & $\begin{array}{l}\theta_{\mathrm{CW}} \\
(\mathrm{K})\end{array}$ \\
\hline $\mathrm{La}_{0.7} \mathrm{Ba}_{0.2} \mathrm{Ca}_{0.1} \mathrm{MnO}_{3}$ & 350 & 4.62 & 4.75 & 355 \\
$\mathrm{La}_{0.7} \mathrm{Ba}_{0.2} \mathrm{Ca}_{0.1} \mathrm{Mn}_{0.95} \mathrm{Al}_{0.05} \mathrm{O}_{3}$ & 321 & 4.57 & 4.61 & 326 \\
$\mathrm{La}_{0.7} \mathrm{Ba}_{0.2} \mathrm{Ca}_{0.1} \mathrm{Mn}_{0.9} \mathrm{Al}_{0.1} \mathrm{O}_{3}$ & 300 & 4.52 & 4.58 & 302
\end{tabular}

The measured saturation moments expressed in Bohr magneton is given by:

$$
M_{\mathrm{Sat}}(\mathrm{cal})=\left(M_{\mathrm{SatMn}^{3+}}\right) \times n_{\mathrm{Mn}^{3+}}+\left(M_{\mathrm{SatMn}^{4+}}\right) \times n_{\mathrm{Mn}^{4+}}
$$

where $M_{\mathrm{SatMn}^{3+}}=4 \mu_{\mathrm{B}}$ and $M_{\mathrm{SatMn}^{4+}}=3 \mu_{\mathrm{B}}$ are the magnetic moments (the orbital contribution is neglected) and $n_{\mathrm{Mn}^{3+}}, n_{\mathrm{Mn}^{4+}}$ are the contents of the $\mathrm{Mn}^{3+}$ and $\mathrm{Mn}^{4+}$ ions, respectively. The values obtained $\left(M_{\mathrm{Sat}}(\mathrm{cal})=3.7 \mu_{\mathrm{B}}, 3.5 \mu_{\mathrm{B}}\right.$ and $\left.3.3 \mu_{\mathrm{B}}\right)$ (per formula unit) for $x=0.0,0.05$ and 0.10 respectively, were so far from the experimental values $\left(M_{\mathrm{Sat}}(\exp )=3.56 \mu_{\mathrm{B}}, 3.45 \mu_{\mathrm{B}}\right.$ and $3.28 \mu_{\mathrm{B}}$ ) per formula unit for $x=0.0,0.05$ and 0.10 , respectively. This suggests that the decrease of magnetization with the increase of (Al) content is not only due to the dilution of magnetic $\mathrm{Mn}^{4+}$ atoms but also due to the weakening of exchange coupling by the cluster formation.

The isothermal magnetization curves around $T_{\mathrm{C}}$ versus the external magnetic field up to $5 \mathrm{~T}$ are shown in Fig. $5(x=0.1)$. The so-called Arrott plot $M^{2}$ versus $\mu_{0} H / M$ in inset Fig. 5 exhibits the positive slope of the curves at all temperatures studied. This indicates that a transition between the magnetically ordered and the paramagnetic phases is of the second order. ${ }^{28}$

The magnetocaloric effect (MCE) is an intrinsic property of magnetic materials. It is the response of the material to the application or removal of magnetic field, which is maximized

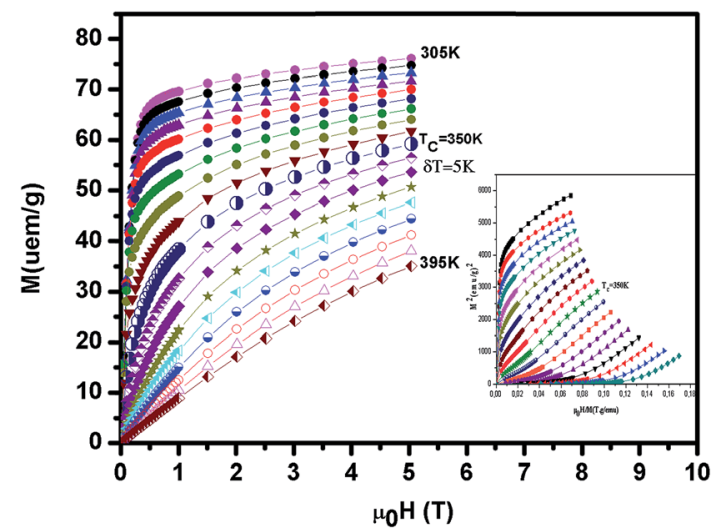

Fig. 5 The isothermal magnetization curves around $T_{C}$ versus external magnetic field up to $5 \mathrm{~T}$ for $\mathrm{La}_{0.7} \mathrm{Ba}_{0.2} \mathrm{Ca}_{0.1} \mathrm{MnO}_{3}$. Inset $M^{2}$ versus $\mu_{0} H / M$ isotherms for this compound.

when the material is near its magnetic ordering temperature (Curie temperature $T_{\mathrm{C}}$ ).

The isothermal magnetic entropy change $\Delta S_{\mathrm{M}}(T)$, which is associated with the magnetocaloric effect, can be calculated from the measurements of magnetization as a function of applied magnetic field and temperature. According to the classical thermodynamics theory, the change in the magnetic entropy produced by varying the magnetic field from zero to $\mu_{0} H$ is given by:

$$
\begin{aligned}
\Delta S_{\mathrm{M}}\left(T, \mu_{0} H\right) & =S_{\mathrm{M}}\left(T, \mu_{0} H\right)-S_{\mathrm{M}}(T, 0) \\
& =\int_{0}^{\mu_{0} H_{\max }}\left(\frac{\partial S}{\partial\left(\mu_{0} H\right)}\right)_{T} \mathrm{~d}\left(\mu_{0} H\right)
\end{aligned}
$$

By using Maxwell's thermodynamic relation:

$$
\left(\frac{\partial S}{\partial\left(\mu_{0} H\right)}\right)_{T}=\left(\frac{\partial M}{\partial T}\right)_{\mu_{0} H}
$$

The magnetic entropy change can be rewritten as follows:

$$
\Delta S_{\mathrm{M}}\left(T, \mu_{0} H\right)=\int_{0}^{\mu_{0} H_{\max }}\left(\frac{\partial M}{\partial T}\right)_{\mu_{0} H} \mathrm{~d}\left(\mu_{0} H\right)
$$

In order to evaluate the MCE, the changes of magnetic entropy $\Delta S_{\mathrm{M}}(T)$ upon application of magnetic fields from the isothermal $M-\mu_{0} H$ curve can be numerically calculated using eqn (6).

$$
\begin{aligned}
\Delta S_{\mathrm{M}}\left(\frac{T_{1}+T_{2}}{2}\right)= & \frac{1}{\left(T_{1}-T_{2}\right)}\left[\int_{0}^{\mu_{0} H_{\max }} M\left(T_{2}, \mu_{0} H\right)_{\mu_{0} H} \mathrm{~d}\left(\mu_{0} H\right)\right. \\
& \left.-\int_{0}^{\mu_{0} H_{\max }} M\left(T_{1}, \mu_{0} H\right)_{\mu_{0} H} \mathrm{~d}\left(\mu_{0} H\right)\right]
\end{aligned}
$$

By using a program carried out in our laboratory based on eqn (6), we have determined magnetic entropy change $\left(-\Delta S_{\mathrm{M}}\right)$ for different applied magnetic field change intervals as seen in 


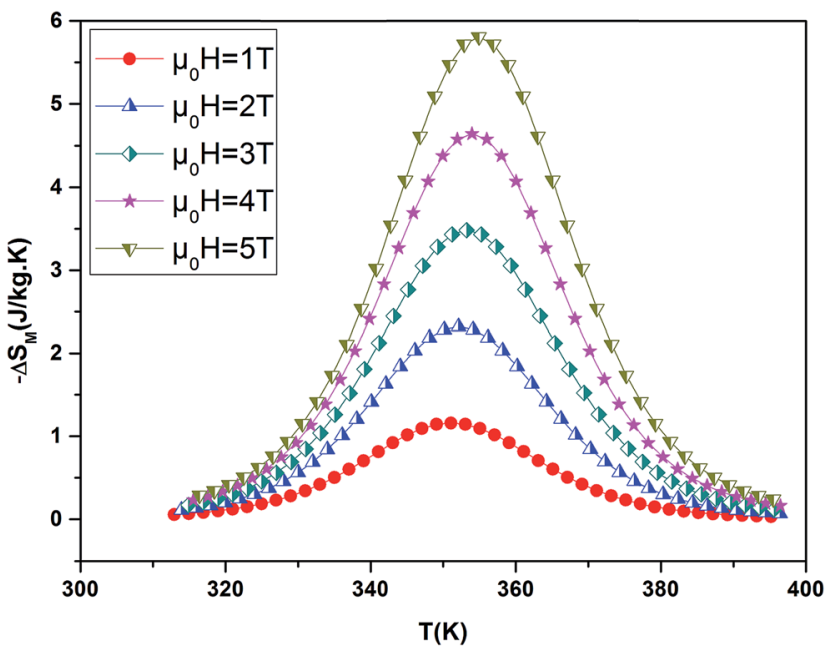

Fig. 6 Magnetic entropy change $\Delta S_{M}$ evolution versus temperature at several magnetic applied for $\mathrm{La}_{0.7} \mathrm{Ba}_{0.2} \mathrm{Ca}_{0.1} \mathrm{MnO}_{3}$ sample.

Fig. 6 for the $\mathrm{La}_{0.7} \mathrm{Ba}_{0.2} \mathrm{Ca}_{0.1} \mathrm{MnO}_{3}$ sample. The compounds are showing large changes in magnetic entropy around Curie temperature $\left(T_{\mathrm{C}}\right)$, which is a characteristic property of simple ferromagnets due to the efficient ordering of magnetic spins at the temperature induced by magnetic field. ${ }^{29}$ The magnitude of $\left(-\Delta S_{\mathrm{M}}(T)\right)$ for all samples increases with increasing the applied magnetic field. For example the different curves of the magnetic entropy change for all our synthesized polycrystalline samples as a function of temperature under $5 \mathrm{~T}$, show that the maximum magnetic-entropy value decreases from $5.8 \mathrm{~J} \mathrm{~kg}^{-1} \mathrm{~K}^{-1}$ for $x=$ 0.00 to $4.85 \mathrm{~J} \mathrm{~kg}^{-1} \mathrm{~K}^{-1}$ for $x=0.10$ near their respective $T_{\mathrm{C}}$. Guo et $a{ }^{30}{ }^{30}$ indicated that the large magnetic entropy change in perovskite manganites could originate from the spin-lattice coupling in the magnetic ordering process. Strong coupling between spin and lattice is corroborated by the observed significant lattice changes accompanying magnetic transition in perovskite manganites. ${ }^{31}$ The lattice structural change in the Mn-O bond distance as well as in the $\langle\mathrm{Mn}-\mathrm{O}-\mathrm{Mn}\rangle$ bond angle would in turn favor the spin ordering. Thus a more abrupt variation of magnetization near Curie temperature $\left(T_{\mathrm{C}}\right)$ occurs, resulting in a large magnetic entropy change as a large MCE. It should be noted that $\left(-\Delta S_{\mathrm{M}}^{\max }\right)$ is not the only parameter deciding about an applicability of material. There is a demand for materials which can transport heat at a relatively large temperature difference between the cold and the hot sinks in the ideal refrigeration cycle. This feature is accounted for by the full width at half maximum $\delta T_{\text {FWHM }}$ of the $\left(-\Delta S_{\mathrm{M}}^{\mathrm{max}}\right)$ curve. Then, the amount of transferred heat may be estimated for an ideal refrigeration cycle by the so-called relative cooling power (RCP) defined by: ${ }^{32}$

$$
\mathrm{RCP}=\left(-\Delta S_{\mathrm{M}}^{\max }\right) \times \delta T_{\mathrm{FWHM}}
$$

where $\delta T_{\text {FWHM }}$ is full width at half maximum of magnetic entropy change curve and $\Delta S_{\mathrm{M}}^{\max }$ is the peak maximum magnetic entropy change. Using the above relation, the RCP values for $\mathrm{La}_{0.7} \mathrm{Ba}_{0.2} \mathrm{Ca}_{0.1} \mathrm{Mn}_{1-x} \mathrm{Al}_{x} \mathrm{O}_{3}$ were $167 \mathrm{~J} \mathrm{~kg}^{-1}(x=0.00)$ and $193 \mathrm{~J} \mathrm{~kg}^{-1}(x=0.10)$. A comparison between, the maximum magnetic entropy change, the Curie temperature and the relative magnetic cooling efficiency of several manganese perovskites which could be used for room temperature magnetic refrigerators is summarized in Table 4.

It is well known that the critical exponents are not defined for first-order transition because the magnetic field can shift the transition, leading to a field-dependent phase boundary $T_{\mathrm{C}}$ $\left(\mu_{0} H\right) .{ }^{33}$ According to the scaling hypothesis, a second-order phase transition near the Curie point $T_{\mathrm{C}}$ is characterized by a set of interrelated critical exponents, $\gamma$ (relevant to the initial magnetic susceptibility $\chi_{0}, \chi_{0}{ }^{-1}(T)=\lim _{H \rightarrow 0}(H / M)$ just above $\left.T_{\mathrm{C}}\right)$, $\delta$ (associated with the critical magnetization isotherm at $T_{\mathrm{C}}$ ) and $\beta$ (associated with the spontaneous magnetization $M_{\mathrm{S}}(T)=\lim _{H \rightarrow 0} M$ just below $\left.T_{\mathrm{C}}\right)$. Mathematically, these critical exponents are obtained, from magnetization measurements through the following asymptotic relations: ${ }^{34}$

$$
\begin{gathered}
M_{\mathrm{S}}(T)=M_{0}|\varepsilon|^{-\beta}, \varepsilon<0, T<T_{\mathrm{C}} \\
\chi_{0}{ }^{-1}(T)=\left(h_{0} / M_{0}\right) \varepsilon^{\gamma}, \varepsilon>0, T>T_{\mathrm{C}}
\end{gathered}
$$

\begin{tabular}{|c|c|c|c|c|c|}
\hline $\mathrm{Gd}_{5}\left(\mathrm{Si}_{2} \mathrm{Ge}_{2}\right)$ & 275 & 18.5 & 535 & 5 & 39 \\
\hline $\mathrm{La}_{0.5} \mathrm{Sm}_{0.1} \mathrm{Sr}_{0.4} \mathrm{Mn}_{0.95} \mathrm{In}_{0.05} \mathrm{O}_{3}$ & 308 & 4.50 & 193.48 & 5 & 40 \\
\hline $\mathrm{La}_{0.57} \mathrm{Y}_{0.1} \mathrm{Ba}_{0.23} \mathrm{Ca}_{0.1} \mathrm{MnO}_{3}$ & 300 & 4.34 & 349 & 5 & 42 \\
\hline $\mathrm{La}_{0.8} \mathrm{Ba}_{0.2} \mathrm{MnO}_{3}$ & 295 & 4.5 & 130 & 5 & 43 \\
\hline $\mathrm{La}_{0.67} \mathrm{Sr}_{0.33} \mathrm{MnO}_{3}$ & 348 & 1.69 & 211 & 5 & 44 \\
\hline $\mathrm{La}_{0.7} \mathrm{Ba}_{0.2} \mathrm{Ca}_{0.1} \mathrm{Mn}_{0.9} \mathrm{Al}_{0.1} \mathrm{O}_{3}$ & 300 & 4.6 & 193 & 5 & This work \\
\hline $\mathrm{La}_{0.7} \mathrm{Sr}_{0.3} \mathrm{Mn}_{0.95} \mathrm{Ti}_{0.05} \mathrm{O}_{3}$ & 308 & 2.2 & 90 & 2 & 45 \\
\hline $\mathrm{La}_{0.7} \mathrm{Sr}_{0.3} \mathrm{Mn}_{0.9} \mathrm{Fe}_{0.1} \mathrm{O}_{3}$ & 260 & 1.7 & 83 & 2 & 46 \\
\hline $\mathrm{La}_{0.7} \mathrm{Ba}_{0.2} \mathrm{Ca}_{0.1} \mathrm{MnO}_{3}$ & 350 & 2.35 & 70 & 2 & This work \\
\hline $\mathrm{La}_{0.7} \mathrm{Ba}_{0.2} \mathrm{Ca}_{0.1} \mathrm{Mn}_{0.95} \mathrm{Al}_{0.05} \mathrm{O}_{3}$ & 321 & 2.12 & 85 & 2 & This work \\
\hline $\mathrm{La}_{0.7} \mathrm{Ba}_{0.2} \mathrm{Ca}_{0.1} \mathrm{Mn}_{0.9} \mathrm{Al}_{0.1} \mathrm{O}_{3}$ & 300 & 1.86 & 96 & 2 & This work \\
\hline
\end{tabular}

Table 4 Summary of magnetocaloric properties of $\mathrm{La}_{0.7} \mathrm{Ba}_{0.2} \mathrm{Ca}_{0.1} \mathrm{Mn}_{1-x} \mathrm{Al}_{x} \mathrm{O}_{3}(0 \leq x \leq 0.1)$ compared with other magnetic materials 

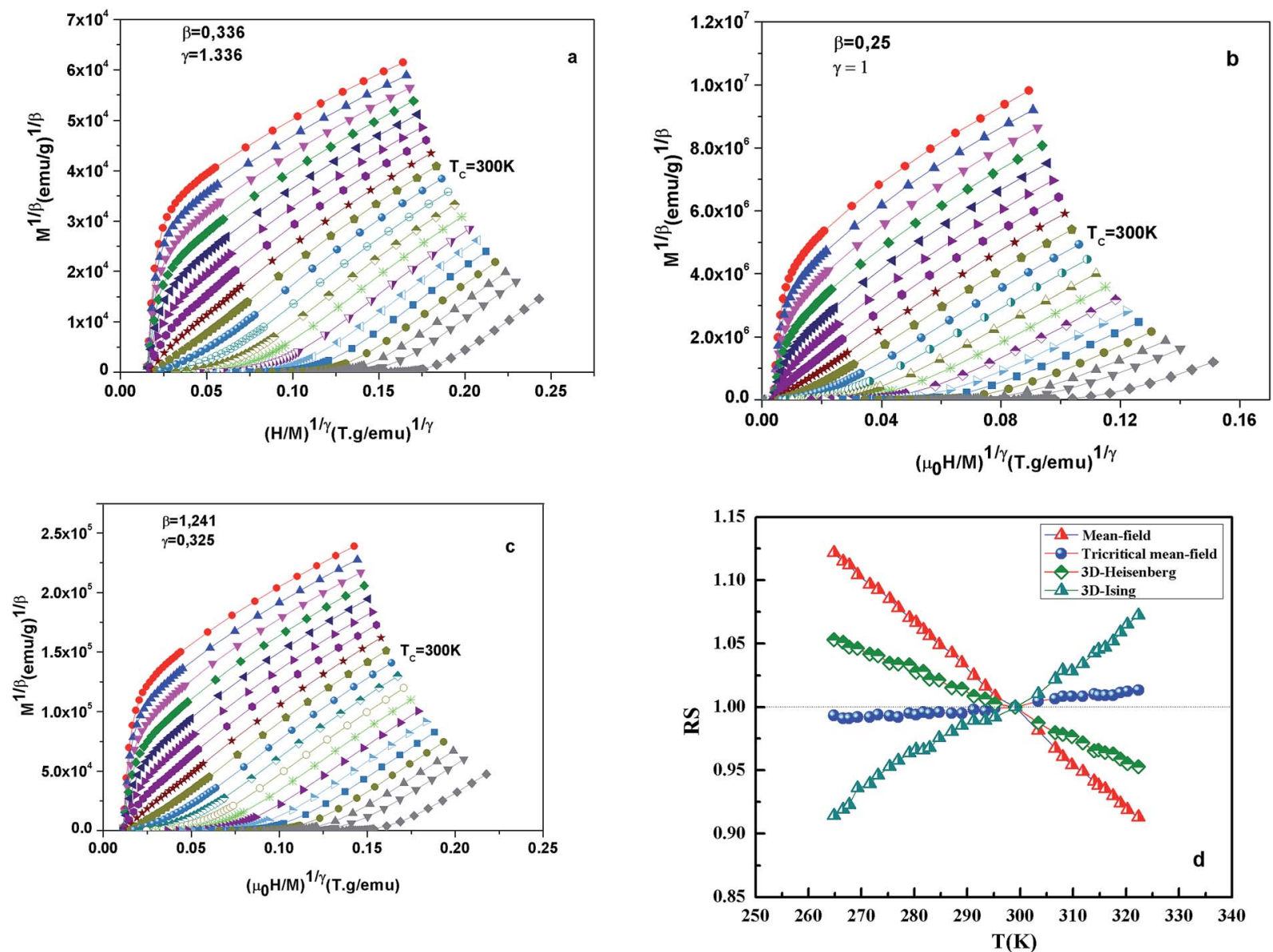

Fig. 7 Modified Arrott plot isotherms of $M^{1 / \beta}$ vs. $(H / M)^{1 / \gamma}$ for $x=0.1$ sample, with (a) 3D Heisenberg model $(\beta=0.365$ and $\gamma=1.336)$; (b) tricritical mean-field model ( $\beta=0.25$ and $\gamma=1$ ); (c) 3D Ising-model ( $\beta=0.325$ and $\gamma=1.24$ ); and (d) RS vs. temperatures.

$$
M=D H^{1 / \delta}, \varepsilon=0, T=T_{\mathrm{C}}
$$

where $M_{0}, h_{0} / M_{0}$ and $D$ are the critical amplitudes, and $\varepsilon$ is the reduced temperature $\left(\varepsilon=\left(T-T_{\mathrm{C}}\right) / T_{\mathrm{C}}\right)$.

Inset at Fig. 5 shows the Arrott plot $M^{2} v s . \mu_{0} H / M$ constructed from the raw $M-\mu_{0} H$ isotherms after correcting the external magnetic field for demagnetization effects. According to mean- field theory $(\beta=0.5, \gamma=1$ and $\delta=3)$ for a phase transition, which is far from a tricritical point, near $T_{\mathrm{c}}$ these curves should show a series of straight lines for different temperatures and the line at $T=T_{\mathrm{c}}$ should pass through the origin. In our work, the curves in the Arrott plot shows a nonlinear and concave behavior even in the high field indicating the mean-field theory for the above class of phase transitions is invalid.
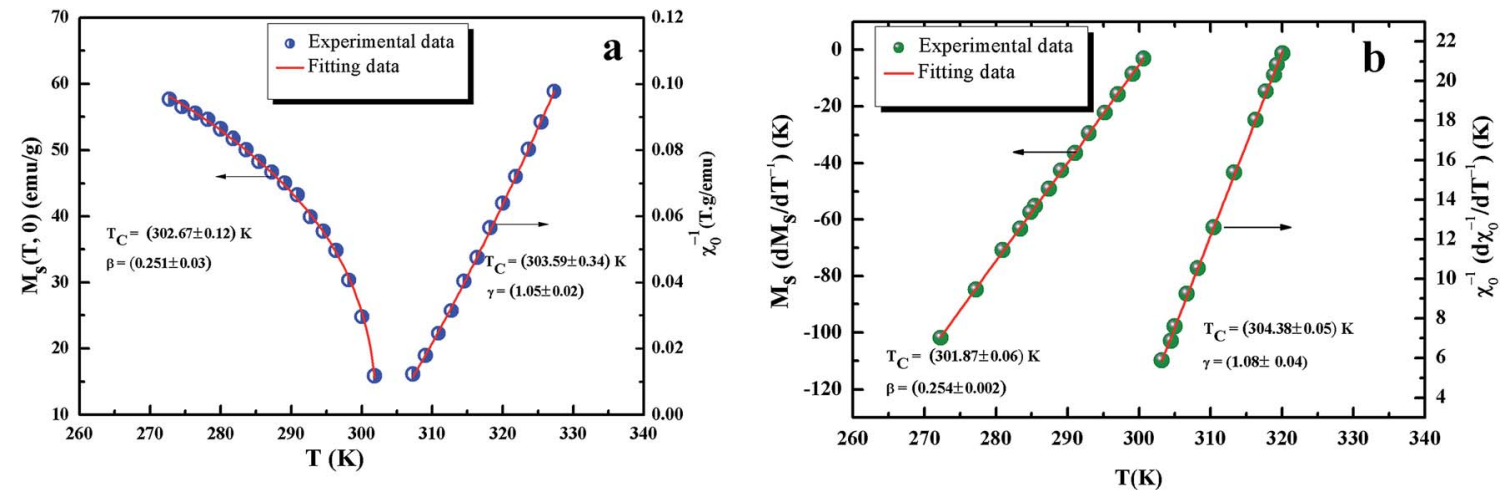

Fig. 8 Kouvel Fisher plots for the spontaneous magnetization $M_{S}(t)$ (left) and the inverse initial susceptibility $\chi_{0}{ }^{-1}(T)$ (right) were fitted to eqn (7) and (8), for $x=0.1$ sample. 


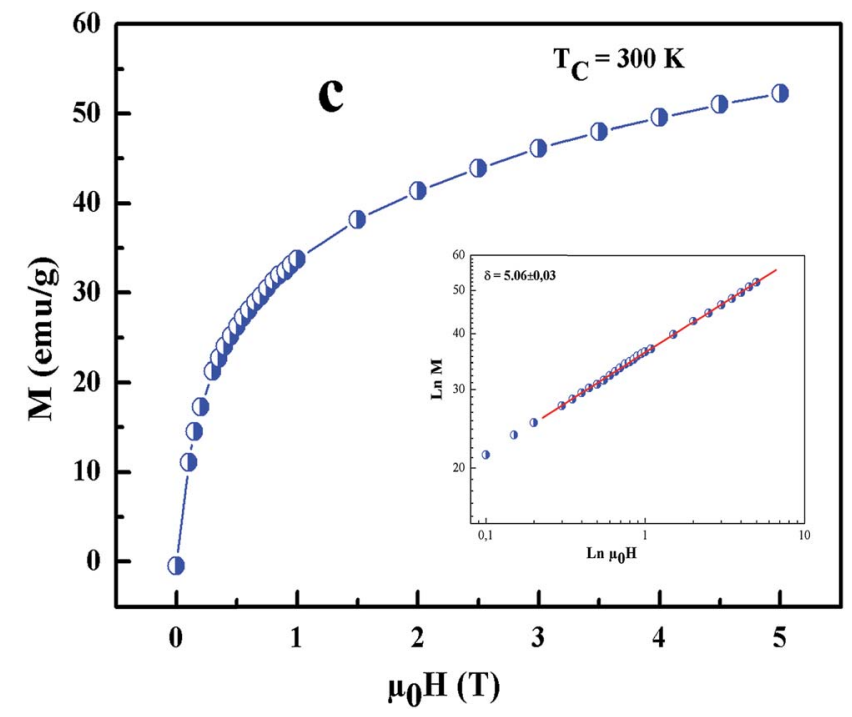

Fig. 9 Isothermal $M$ vs. $\mu_{0} H$ plot of $x=0.1$ sample at $T_{C}=300 \mathrm{~K}$; the inset shows the same plot in log-log scale and the solid line (red color) is the linear fit following eqn (3).

The mean field approximation can be generalized to the socalled modified Arrott plot (MAP) expression, based on the Arrott-Koakes equation of state ${ }^{35}$

$$
(H / M)^{1 / \gamma}=a\left(T-T_{\mathrm{c}}\right) / T+b M^{1 / \beta}
$$

where $a$ and $b$ are considered to be constants.

Fig. 7 shows the modified Arrott plots of $M^{1 / \beta} v s .(H / M)^{1 / \gamma}$, based on the Arrott-Noakes equation of state eqn (11), at different temperatures for the $x=0.1$ by using three models of critical exponents: 3D Heisenberg model $(\beta=0.365, \gamma=1.336)$ in Fig. $7(\mathrm{a})$, tricritical mean field $(\beta=0.25, \gamma=1)$ in Fig. $7(\mathrm{~b})$ and 3D Ising $(\beta=0.325, \gamma=1.24)$ in Fig. $7(\mathrm{c})$.

We choose the best model which gave straight lines and nearly parallel in the region of high field.

All curves yield quasi straight lines in the high-field region. To compare these results, we calculated the so-called relative slope (RS) defined at the critical point as $\mathrm{RS}=S(T) / S\left(T_{\mathrm{c}}\right)$. Since the MAP is a series of parallel lines, the RS of the most satisfactory model should be close to 1 (unity). The RS vs. $T(x=0.1)$ for the three models are shown in Fig. 7(d). One can see in this figure that the tricritical model is the best one for the determination of the critical exponents for $x=0.1$ sample. The high field straight line portions of the isotherms in Fig. 7(b) can be linearly extrapolated to obtain the spontaneous magnetization $M_{\mathrm{S}}(T, 0)$ and the inverse susceptibility $1 / \chi_{0}(T)$. The temperature dependence of $M_{\mathrm{S}}(T, 0)$ and $1 / \chi_{0}(T)$ for the sample with $x=0.1$ are shown in Fig. 8. Similarly, we can also obtain $M_{\mathrm{S}}(T, 0)$ vs. $T$ and $1 / \chi_{0}(T) v s$. $T$, for samples with $x=0$ and 0.05 (not shown here). The continuous curves in Fig. 8 denote the power law fitting of $M_{\mathrm{S}}(T, 0) v s . T$ and $1 / \chi_{0}(T) v s . T$ according to eqn (8) and (9), respectively. This gives the values of $\beta=0.251 \pm 0.03$ with $T_{\mathrm{c}}=302.46 \pm 0.33 \mathrm{~K}$ and $\gamma=1.05 \pm 0.02$ with $T_{\mathrm{c}}=303.59 \pm 0.34$ K. Alternatively, the values of $T_{\mathrm{c}}, \beta$ and $\gamma$ are also obtained by Kouvel-Fisher (KF) method. ${ }^{36}$ According to this method, plots of $M_{\mathrm{S}}(T)\left[\mathrm{d} M_{\mathrm{S}}(T) / \mathrm{d} T\right]^{-1} \quad$ vs. $T$ and $\chi_{0}{ }^{-1}(T)\left[\mathrm{d} \chi_{0}{ }^{-1}(T) / \mathrm{d} T\right]^{-1} \quad$ vs. $\quad T$ should yield straight lines with slopes of $1 / \beta$ and $1 / \gamma$, respectively. The linear fitting to the plots following the KF method gives $\beta=0.249 \pm 0.003$ with $T_{\mathrm{C}}=301.15 \pm 0.04 \mathrm{~K}$ and $\gamma=1.09$ \pm 0.04 with $T_{\mathrm{C}}=303 \pm 0.06 \mathrm{~K}$ for $x=0.1$ sample (Fig. 8).

Table 5 Comparison of the values of the critical exponents of $\mathrm{La}_{0.7} \mathrm{Ba}_{0.2} \mathrm{Ca}_{0.1} \mathrm{Mn}_{1-x} \mathrm{Al}_{x} \mathrm{O}_{3}(x=0,0.05$ and 0.1$)$ compounds (this work) with earlier reports and with the various theoretical models

\begin{tabular}{|c|c|c|c|c|c|c|}
\hline Material & Technique & $T_{\mathrm{C}}(\mathrm{K})$ & $\beta$ & $\gamma$ & $\delta$ & Ref. \\
\hline Mean-field model & Theory & & 0.5 & 1.0 & 3.0 & 47 \\
\hline 3D-Heisenberg model & Theory & & $0.365 \pm 0.003$ & $1.336 \pm 0.004$ & $4.80 \pm 0.04$ & 47 \\
\hline 3D-Ising model & Theory & & $0.325 \pm 0.002$ & $1.241 \pm 0.002$ & $4.82 \pm 0.02$ & 47 \\
\hline Tricritical mean-field model & Theory & & 0.25 & 1 & 5 & 47 \\
\hline \multirow[t]{4}{*}{$\mathrm{La}_{0.7} \mathrm{Ba}_{0.2} \mathrm{Ca}_{0.1} \mathrm{MnO}_{3}$} & MAP & $354.02 \pm 0.04$ & $0.253 \pm 0.002$ & $1.12 \pm 0.03$ & - & This work \\
\hline & $\mathrm{KF}$ & $351.23 \pm 0.04$ & $0.248 \pm 0.04$ & $1.01 \pm 0.04$ & - & This work \\
\hline & C.I (cal) & - & - & - & $5.07 \pm 0.02$ & This work \\
\hline & C.I (exp) & - & - & - & $4.89 \pm 0.01$ & This work \\
\hline \multirow{4}{*}{$\mathrm{La}_{0.7} \mathrm{Ba}_{0.2} \mathrm{Ca}_{0.1} \mathrm{Mn}_{0.95} \mathrm{Al}_{0.05} \mathrm{O}_{3}$} & MAP & $322.35 \pm 0.06$ & $0.253 \pm 0.001$ & $1.04 \pm 0.02$ & - & This work \\
\hline & $\mathrm{KF}$ & $321.02 \pm 0.01$ & $0.246 \pm 0.3$ & $1.08 \pm 0.05$ & - & This work \\
\hline & C.I (cal) & - & - & - & $5.11 \pm 0.03$ & This work \\
\hline & C.I (exp) & - & - & - & $4.97 \pm 0.03$ & This work \\
\hline \multirow[t]{4}{*}{$\mathrm{La}_{0.7} \mathrm{Ba}_{0.2} \mathrm{Ca}_{0.1} \mathrm{Mn}_{0.9} \mathrm{Al}_{0.1} \mathrm{O}_{3}$} & MAP & $302.46 \pm 0.33$ & $0.251 \pm 0.03$ & $1.05 \pm 0.02$ & - & This work \\
\hline & $\mathrm{KF}$ & $301.15 \pm 0.04$ & $0.249 \pm 0.003$ & $1.09 \pm 0.04$ & - & This work \\
\hline & C.I (cal) & - & - & - & $5.06 \pm 0.03$ & This work \\
\hline & C.I (exp) & - & - & - & $5.176 \pm 0.004$ & This work \\
\hline $\mathrm{La}_{0.7} \mathrm{~Pb}_{0.05} \mathrm{Na}_{0.25} \mathrm{MnO}_{3}$ & & 334.54 & 0.344 & 1.296 & 4.80 & 48 \\
\hline $\mathrm{La}_{0.7} \mathrm{Sr}_{0.3} \mathrm{MnO}_{3}$ & & 360 & $0.377 \pm 0.004$ & $1.168 \pm 0.006$ & $4.10 \pm 0.01$ & 49 \\
\hline$\left(\mathrm{La}_{0.9} \mathrm{Dy}_{0.1}\right)_{0.8} \mathrm{~Pb}_{0.2} \mathrm{MnO}_{3}$ & & 248 & $0.484 \pm 0.002$ & $0.961 \pm 0.012$ & $2.90 \pm 0.01$ & 50 \\
\hline $\mathrm{Nd}_{0.7} \mathrm{Sr}_{0.3} \mathrm{MnO}_{3}$ & & 238 & $0.271 \pm 0.006$ & $0.922 \pm 0.016$ & 4.5 & 51 \\
\hline $\mathrm{La}_{0.7} \mathrm{Ca}_{0.3} \mathrm{MnO}_{3}$ & & 190 & $0.349 \pm 0.013$ & $1.231 \pm 0.030$ & 4.524 & 52 \\
\hline $\mathrm{La}_{0.7} \mathrm{Ca}_{0.1} \mathrm{Sr}_{0.2} \mathrm{MnO}_{3}$ & & 326 & $0.36 \pm 0.01$ & $1.22 \pm 0.01$ & $4.4 \pm 0.2$ & 53 \\
\hline $\mathrm{La}_{0.7} \mathrm{Ba}_{0.3} \mathrm{MnO}_{3}$ & & 310 & 0.35 & 1.41 & 5.5 & 54 \\
\hline
\end{tabular}


Obviously, the obtained values of the critical exponents and $T_{\mathrm{C}}$ using the KF method are in agreement with that using the modified Arrott plot of tricritical model. The values of $\delta$ were obtained by plotting the critical isotherm at $T_{\mathrm{C}}$. In Fig. 9 the $M$ vs. $\mu_{0} H$ curve at $300 \mathrm{~K}$ was chosen as the critical isotherm based on the previous discussion. The inset of Fig. 9 shows the same curve $M$ vs. $\mu_{0} H$ on a log-log scale. The solid straight line with a slope $1 / \delta$ is the fitting result by using eqn (10). From the linear fit, we obtained the third critical exponent $\delta=5.06$ for $x=0.1$ (Table 5). According to statistical theory, these three critical exponents must fulfill the Widom scaling relation: ${ }^{37}$

$$
\delta=1+\frac{\gamma}{\beta}
$$

Using the above determined values of $\beta$ and $\gamma$, eqn (12) yields $\delta=5.176(x=0.1)$ for $\beta$ and $\gamma$ evaluated according to Fig. 9. Thus the critical exponents found in this study obey the Widom scaling relation remarkably well. In the critical region, the magnetic equation of state is given by:

$$
M(H, \varepsilon)=\varepsilon^{\beta} f_{ \pm}\left(H / \varepsilon^{\beta+\gamma}\right)
$$

where $f_{+}$for $T>T_{\mathrm{C}}$ and $f_{-}$for $T<T_{\mathrm{C}}$ are regular analytic functions. Eqn (13) implies that $M / \varepsilon^{\beta}$ vs. $H / \varepsilon^{\beta+\gamma}$ yields two universal curves, one for temperature below $T_{\mathrm{C}}$ and the other for temperature above $T_{\mathrm{C}}$. Fig. 10 shows plot of $M|\varepsilon|^{-\beta}$ vs. $H|\varepsilon|^{-(\beta+\gamma)}$ for $(x=0.1)$ using the values of $\beta, \gamma$ and $\delta$ obtained by the KF method. It can be clearly seen that all the points fall two curves, one for $T<T_{\mathrm{C}}$ another one $T>T_{\mathrm{C}}$. This suggests that the value of the exponents and $T_{\mathrm{c}}$ are reasonably accurate. The obtained critical exponents of $\mathrm{La}_{0.7} \mathrm{Ba}_{0.2} \mathrm{Ca}_{0.1} \mathrm{Mn}_{1-x} \mathrm{Al}_{x} \mathrm{O}_{3}(0<x<0.1)$ (present work) and the theoretical values of different theoretic models, are listed in Table 5 for comparison. The values of the critical parameters depend on the range of the exchange interaction $J(r)$. Fisher et al. ${ }^{38}$ have performed a renormalization group analysis of systems with an exchange interaction of the

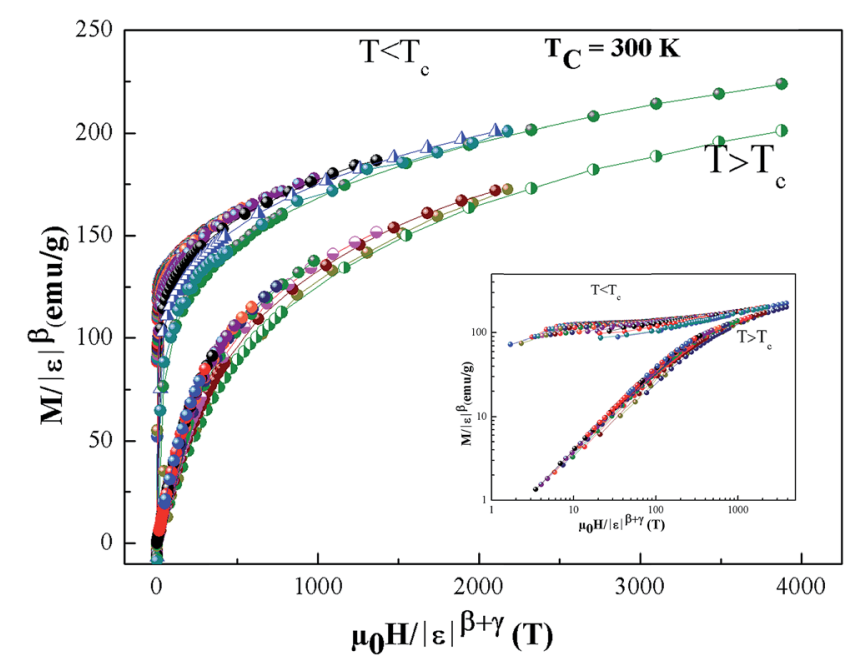

Fig. 10 Scaling plots of $M|\varepsilon|^{-\beta}$ as function of $|\varepsilon|^{-(\beta+\gamma)}$, indicating two universal curves below and above $T_{C}$. The inset shows the same plots on a log-log scale. form $J(r)=1 / r^{d+\sigma}$ ( $d$ is the dimension of the system; $\sigma$ is the range of the interaction). If $\sigma$ is greater than two, the Heisenberg framework is valid for a 3D-isotropic ferromagnet. However, if $\sigma$ $<3 / 2$, it is the mean field framework, which is valid. In the intermediate range of $3 / 2 \leq \sigma \leq 2$ the FM behaviour belongs to different universality classes depending on $\sigma$.

\section{Conclusion}

In summary, we have investigated the structure, magnetic and magnetocaloric properties of perovskite $\mathrm{La}_{0.7} \mathrm{Ba}_{0.2} \mathrm{Ca}_{0.1} \mathrm{Mn}_{1-x^{-}}$ $\mathrm{Al}_{x} \mathrm{O}_{3}(0 \leq x \leq 0.1)$ compounds. There is no structural transition due to substitution of $\mathrm{Mn}^{3+}$ by $\mathrm{Al}^{3+}$. All the samples crystallize in a rhombohedral structure $(R \overline{3} c)$ with a decrease in the unit cell volume as $\left\langle r_{\mathrm{B}}\right\rangle$ decreases. They exhibit a paramagnetic-ferromagnetic transition when temperature decreases. It was found that the maximum value of the magnetic entropy change $\Delta S_{\mathrm{M}}^{\max }$ decreases with increasing Al concentration. A large magnetocaloric effect is observed in these samples. Since RCP represents a good factor for comparing magnetocaloric materials, the $\mathrm{La}_{0.7} \mathrm{Ba}_{0.2} \mathrm{Ca}_{0.1} \mathrm{Mn}_{0.9} \mathrm{Al}_{0.1} \mathrm{O}_{3}$ sample looks very promising due to its high RCP $=193 \mathrm{~J} \mathrm{~kg}^{-1}$ and $T_{\mathrm{C}}=300 \mathrm{~K}$. A detailed investigation of critical exponent properties of polycrystalline $\mathrm{La}_{0.7} \mathrm{Ba}_{0.2} \mathrm{Ca}_{0.1} \mathrm{Mn}_{1-x} \mathrm{Al}_{x} \mathrm{O}_{3}(0 \leq x \leq 0.1)$ compounds has been carried out. By means of the modified Arrott plot and Kouvel Fisher method, we have determined the critical exponents $\beta, \gamma$ and $\delta$, which are in a good agreement with the magnetic equation state. The results showed that the tricritical mean-field model is satisfied, indicating short range-interactions.

\section{Conflicts of interest}

There are no conflicts to declare.

\section{Acknowledgements}

The authors would like to thank Deanship of Scientific Research at Majmaah University for supporting this work under Project Number No: 37/14.

\section{References}

1 J. Khelifi, A. Tozri, F. Issaoui, E. Dhahri and E. K. Hlil, J. Alloys Compd., 2014, 584, 617-624.

2 R. N. Mahato, K. Sethupathi, V. Sankaranarayanan and R. Nirmala, J. Appl. Phys., 2010, 107, 09A943.

3 K. Cherif, J. Dhahri, E. Dhahri, M. Oumezzine and H. Vincent, J. Solid State Chem., 2002, 163, 466-471.

4 L. Joshi and S. Keshri, Measurement, 2011, 44, 938-945.

5 S. S. Ata-Allah, M. F. Mostafa, Z. Heiba and H. S. Refai, Phys. $B, 2011,406,801-811$.

6 C. Zener, Phys. Rev., 1951, 81, 440.

7 R. Cabassi, F. Bolzoni, A. Gauzzi and F. Licci, Phys. Rev. B: Condens. Matter Mater. Phys., 2006, 74, 184425.

8 M. Fähnle, W. U. Kellner and H. Kronmüller, Phys. Rev. B: Condens. Matter Mater. Phys., 1987, 35, 3640. 
9 H. E. Stanley, Introduction to phase Transitions and Critical Phenomena, Oxford University Press, London, 1971.

10 J. L. Alonso, L. A. Fernandez, F. Guinea, V. Laliena and V. Martin-Mayor, Nucl. Phys. B, 2001, 596, 587.

11 A. K. Pramanik and A. Banerjee, Phys. Rev. B: Condens. Matter Mater. Phys., 2009, 79, 214426.

12 Y. Motome and N. Furukawa, J. Phys. Soc. Jpn., 2001, 70, 1487.

13 Y. Motome and N. Furukawa, J. Phys. Soc. Jpn., 2000, 69, 3785.

14 K. Ghosh, C. J. Lobb, R. L. Greene, S. G. Karabashev, D. A. Shulyatev, A. A. Arsenov and Y. Mukovskii, Phys. Rev. Lett., 1998, 81, 4740.

15 Ch. V. Mohan, M. Seeger, H. Kronmuller, P. Murugaraj and J. Maier, J. Magn. Magn. Mater., 1998, 183, 348.

16 H. S. Shin, J. E. Lee, Y. S. Nam, H. L. Ju and C. W. Park, Solid State Commun., 2001, 118, 377.

17 J. Rodriguez Carvajal, FULLPROF2000-2005, Laboratoire Leon Briouillon (CEA-CNRS).

18 R. D. Schannon, Acta Crystallogr., Sect. A: Cryst. Phys., Diffr., Theor. Gen. Crystallogr., 1976, 32, 751-767.

19 E. Rodriguez, I. Alvarez, M. L. Lopez, M. L. Veiga and C. Pico, J. Solid State Chem., 1999, 148, 479-486.

20 M. O'Keeffe and B. G. Hyde, Acta Crystallogr., Sect. B: Struct. Crystallogr. Cryst. Chem., 1977, 33, 3802-3813.

21 A. Tozri, E. Dhahri and E. K. Hlil, Phys. Lett. A, 2011, 375, 1528-1533.

22 M. A. Gdaiem, S. Ghodhbane, Ah. Dhahri, J. Dhahri and E. K. Hlil, J. Alloys Compd., 2016, 681, 547-55420.

23 M. Dhahri, A. Zaidi, K. Cherif, J. Dhahri and E. K. Hlil, J. Alloys Compd., 2017, 691, 578-586.

24 P. G. Radaelli, G. Iannone, M. Marezio, H. Y. Hwang, S.-W. Cheong, J. D. Jorgensen and D. N. Argyriou, Phys. Rev. B: Condens. Matter Mater. Phys., 1997, 56, 8265.

25 C. Vazquez-Vazquez and M. A. Lopez-Quintela, J. Solid State Chem., 2006, 179, 3229-3237.

26 A. h. Dhahri, E. Dhahri and E. K. Hlil, Appl. Phys. A: Mater. Sci. Process., 2014, 116, 2077-2085.

27 S. L. Ye, W. H. Song, J. M. Dai, K. Y. Wang and J. J. Du, J. Appl. Phys., 2001, 90, 2943.

28 S. K. Banerjee, Phys. Lett., 1964, 12, 16.

29 A. Bhattacharyya, S. Chatterjee, S. Giri and S. Majumdar, Eur. Phys. J. B, 2009, 70, 347.

30 Z. B. Guo, Y. M. Du, J. S. Zhu, H. Huang, W. P. Ding and D. Feng, Phys. Rev. Lett., 1997, 78, 1142.

31 P. G. Radaelli, D. E. Cox, M. Marezio, S. W. Cheong, P. E. Schiffer and A. P. Ramirez, Phys. Rev. Lett., 1995, 75, 4488.
32 M. Abassi, N. Dhahri, J. Dhahri and E. K. Hlil, Phys. B, 2014, 449, 138-143.

33 T. L. Phan, P. Q. Thanh, N. H. Sinh, K. W. Lee and S. C. Yu, Curr. Appl. Phys., 2011, 11, 830.

34 K. Huang, Statistical Mechanics, Wiley, New York, 1987.

35 A. Arrott and J. E. Noakes, Phys. Rev. Lett., 1967, 19, 786.

36 J. S. Kouvel and M. E. Fisher, Phys. Rev., 1964, 136, A1626.

37 H. S. Shin, J. E. Lee, Y. S. Nam, H. L. Ju and C. W. Park, Solid State Commun., 2001, 118, 377.

38 M. E. Fisher, S.-K. Ma and B. G. Nickel, Phys. Rev. Lett., 1972, 29, 917-920.

39 K. A. Gschneidner Jr, V. K. Pecharsky and A. O. Tsokol, Rep. Prog. Phys., 2005, 68, 1479.

40 M. Dhahri, A. Zaidi, K. Cherif, J. Dhahri and E. K. Hlil, J. Alloys Compd., 2017, 691, 578-586.

41 Y. Sun, W. Tong and Y. Zhang, J. Magn. Magn. Mater., 2001, 232, 205-208.

42 M. Abassi, N. Dhahri, J. Dhahri and E. K. HLIL, Phys. B, 2014, 449, 138-143.

43 S. Ghodhbane, A. Dhahri, N. Dhahri, E. K. Hlil and J. Dhahri, J. Alloys Compd., 2013, 550, 364.

44 S. Zemni, M. Baazaoui, J. Dhahri, H. Vincent and M. Oumezzine, J. Mater. Lett., 2009, 63, 489.

45 D. N. H. Nam, N. V. Dai, L. V. Hong, N. X. Phuc, S. C. Yu, M. Tachibana and E. Takayama- Muromachi, J. Appl. Phys, 2008, 103, 043905.

46 S. K. Barik, C. Krishnamoorthi and R. Mahendiran, J. Magn. Magn. Mater., 2011, 323, 1015-1021.

47 S. E. L. Kossi, S. Mnefgui, J. Dhahri and E. K. Hlil, Ceram. Int., 2015, 41, 8331-8340.

48 A. Tozri, E. Dhahri, E. K. Hlil and M. A. Valente, Solid State Commun., 2011, 151, 315-320.

49 T. D. Thanh, D. C. Linh, T. V. Manh, T. A. Ho, T.-L. Phan and S. C. Yu, J. Appl. Phys., 2015, 117, $17 \mathrm{C} 101$.

50 T. A. Ho, T. L. Phan, P. D. Thang and S. C. Yu, J. Electron. Mater., 2015, 45, 2328-2333.

51 T.-L. Phan, T. A. Ho, P. D. Thang, Q. T. Tran, T. D. Thanh, N. X. Phuc, M. H. Phan, B. T. Huy and S. C. Yu, J. Alloys Compd., 2014, 615, 937-945.

52 P. Zhang, P. Lampen, T. L. Phan, S. C. Yu, T. D. Thanh, N. H. Dan, V. D. Lam, H. Srikanth and M. H. Phan, J. Magn. Magn. Mater., 2013, 348, 146-153.

53 M. H. Phan, V. Franco, N. S. Bingham, H. Srikanth, N. H. Hur and S. C. Yu, J. Alloys Compd., 2010, 508, 238-244.

54 T. A. Ho, M. H. Phan, N. X. Phuc, V. D. Lam, T. L. Phan and S. C. Yu, J. Electron. Mater., 2016, 45, 2508. 